F. Child Lang. 33 (2006), I45-161. (C) 2006 Cambridge University Press doi:I0.1017/So305000905007154 Printed in the United Kingdom

\title{
Word learning deficit among Chinese dyslexic children*
}

\author{
CONNIE SUK-HAN HO \\ The University of Hong Kong, Pokfulam \\ DAVID W. CHAN \\ The Chinese University of Hong Kong \\ SUK-MAN TSANG, SUK-HAN LEE \\ Education and Manpower Bureau, Hong Kong SAR Government \\ AND \\ KEVIN K. H. CHUNG \\ The University of Hong Kong, Pokfulam \\ (Received I4 September 2004. Revised I2 August 2005)
}

ABSTRACT

The present study examined word learning difficulties in Chinese dyslexic children, readers of a nonalphabetic script. A total of I05 Hong Kong Chinese children were recruited and divided into three groups: Dyslexic (mean age 8;8), CA control (mean age 8;9), and RL control (mean age 6; II). They were given a word learning task and a familiar word writing task. It was found that the Dyslexic group performed less well than the RL group in learning irregular words over trials but not the regular ones. Error analyses showed that the Dyslexic group made more orthographic and word association errors but less intra-wordlist interference errors than the RL control group. The Dyslexic group also performed significantly less well than both control groups in writing familiar words (e.g. their own name). These findings suggest that Chinese dyslexic children have difficulty learning new words, especially irregular ones, and retaining overlearned words in

[*] The present study was supported by the Quality Education Fund (\#I 999/2742) in Hong Kong. The authors would like to thank all the participants and their parents in this study. Address for correspondence: Connie Suk-Han Ho, Department of Psychology, The University of Hong Kong, Pokfulam Road, Hong Kong. e-mail: shhoc@hkucc. hku.hk; fax: (852) $285^{8} 35$ I 8 ; tel: (852) 224I 5652. 
long-term memory. We conclude that Chinese dyslexic children have a specific impairment in word learning like their alphabetic counterparts.

\section{INTRODUCTION}

Children's ability to learn to read has been a focus of many studies in the field of child psychology. Some children learn to read well naturally just as they learn to speak easily, while others learn to recognize words with great effort and difficulty. Researchers have been interested in knowing why some children, particularly those with developmental dyslexia (also called reading disability), do not read well. Developmental dyslexia has been defined by the International Dyslexia Association (formerly called the Orton Dyslexia Society) as 'a specific language-based disorder of constitutional origin characterized by difficulties in single word decoding, usually reflecting insufficient phonological processing. These difficulties in single word decoding are often unexpected in relation to age and other cognitive and academic abilities' (the former Orton Dyslexia Society Research Committee April, I994; see Lyon, I 995 for detailed discussion).

Much investigation work has been carried out across different languages in examining the cognitive deficits of dyslexic children that lead to their problems in reading and spelling. As suggested by the definition given above, research findings generally show that the main difficulty of Englishspeaking dyslexic readers lies in phonological processing (e.g. Bradley \& Bryant, I978; Olson, Rack \& Forsberg, I990; Hulme \& Snowling, I 992). These children normally perform poorly in nonword reading and phoneme segmentation. Apart from phonological difficulties, researchers have also found that difficulty in naming visually presented materials rapidly is the second core deficit of these children (e.g. Bowers \& Wolf, r993; Badian, I 995). However, the pattern may be different for readers of other languages as there appear to have different manifestations of dyslexia in different languages (e.g. Miles, 2000). For instance, in the case of nonalphabetic Chinese, Ho and her colleagues examined the relative contributions of rapid naming, phonological, visual, and orthographic skills to the reading problems of Chinese dyslexic children in Hong Kong. They found that rapid naming and orthographic deficits were the two most dominant types of cognitive deficits among the Chinese dyslexic children (Ho, Chan, Tsang \& Lee, 2002; Ho, Chan, Lee, Tsang \& Luan, 2004). It appears that rapid naming deficit is an important contributor to reading failures especially among Chinese readers. So what is the nature of this particular deficit?

Manis, Seidenberg \& Doi (r999) have suggested that RAN (rapid automatized naming) taps into a unique aspect of reading that is not captured by phonological awareness tasks, i.e. the ability to learn arbitrary associations between print and sound. This learning ability is believed to be 
particularly central to beginning readers of any language as well as readers of languages with rather arbitrary associations between script and sound, like Chinese. Wimmer \& Mayringer (200I) have also suggested that impairment in visual-orthographic representation may be due to impaired association formation between visual and phonological representations. It follows from these findings and observations that poor orthographic knowledge and weak associate learning ability may be two possible causes for the high incidence of rapid naming deficit in Chinese dyslexic children. The aim of the present study was to examine whether Chinese dyslexic children were deficient in these two areas. To have a better understanding of the issue, we will next review research related to learning in general and paired-associate learning in particular among alphabetic dyslexic readers.

\section{LEARNING DEFICIT IN ALPHABETIC DYSLEXIC READERS}

Nicolson and Fawcett (I990) have put forward the DYsLExiC automatization Deficit (DAD) hypothesis, suggesting that dyslexic readers may suffer from difficulties of general skill automatization. Later, they further suggested that some general deficits within the learning process might be an alternative to the DAD hypothesis (Nicolson \& Fawcett, 2000). They compared a group of dyslexic children and a group of normal children on their long-term learning of a keyboard spatial task and a choice reaction task to see whether there were any learning differences unrelated to phonological or sensory processing. As expected, the dyslexic children showed impairment in initial and final performance, especially in learning complex skills. However, their resistance to unlearning and ease of relearning were comparable to those of normal children. These findings suggest that dyslexic readers have particular difficulties acquiring new skills. Once the skill has been acquired, however, the rate of forgetting/retention in dyslexic children seems to be similar to that of normal readers. Findings in other studies have shown that the learning deficit of dyslexic readers is especially significant in learning verbal materials and paired-associate learning.

In fact most types of learning involve the forming of associations between two or more units. The ability to learn associations is fundamental to all learning, including word learning. In learning to read words, pairedassociate learning is required to establish the essential letter-sound and letter-name knowledge. For instance, Windfuhr \& Snowling (200I) reported that paired-associate learning (learning the association between abstract visual shapes and spoken nonwords) accounted for unique variance of word recognition in normally achieving children even when performance in nonword reading was controlled. Other studies have also reported difficulties of visual-verbal paired-associate learning (especially for nonwords 
and unfamiliar words) in alphabetic poor or dyslexic readers (e.g. Vellutino, Scanlon \& Spearing, I995; Mayringer \& Wimmer, 2000; Messbauer, de Jong \& van der Leij, 2002; Messbauer \& de Jong, 2003), but dyslexic readers appear to be adequate in forming visual-visual associations (e.g. Liberman, Mann, Shankweiler \& Werfman, I982; Messbauer \& de Jong, 2003). Mayringer and Wimmer (2000) have suggested that the poor performance of these readers in visual-verbal learning tasks is due to their difficulty in acquiring new phonological forms and retaining them in longterm memory.

There is some evidence that dyslexic readers tend to have word learning problems (e.g. Vellutino, Scanlon \& Bentley, I983; Messbauer et al., 2002). We consider word learning as a specific instance of visual-verbal pairedassociate learning. The above findings may suggest that dyslexic readers have difficulty in learning visual-verbal associations and this in turn adversely affects their word learning (Messbauer \& de Jong, 2003). Since most of these studies have been conducted with alphabetic readers, we would like to examine whether Chinese dyslexic readers also exhibit a similar learning deficit.

\section{DEVELOPMENTAL DYSLEXIA IN CHINESE}

The present study examined developmental dyslexia in learners of Chinese. Since the reader may not be familiar with the Chinese language, we will now briefly describe the main characteristics of the Chinese orthography, and then review relevant studies about cognitive deficits in Chinese developmental dyslexia and paired-associate learning in Chinese children.

\section{Characteristics of the Chinese orthography}

The basic graphic unit in Chinese is a character. Each Chinese character represents the smallest unit of meaning (i.e. morpheme), and characters are monosyllabic. There are many homophones at the character level. To avoid the problem of homophones, the majority of words are multisyllabic and about two-thirds of them are bisyllabic (Taylor \& Taylor, I 995). Chinese is not as logographic as people think. Only a small percentage of Chinese characters convey meaning by pictographic or ideographic representation (Hoosain, I99I). According to Kang (r 993), about $80 \%$ to $90 \%$ of Chinese characters are ideophonetic compounds, each comprising a semantic and a phonetic component (also known as 'radical'). Many semantic and phonetic radicals are themselves integrated characters with independent sound and meaning, and some of them are bound forms that only appear as components in compound characters. Semantic radicals usually occupy the left or top position of characters with a left-right structure (e.g. 清 'clear') 
or top-bottom structure (e.g. 草 'grass') respectively. Semantic radicals usually provide cues about the semantic category of a character. For instance, in the character 燈 [dang $]^{1}$ 'lamp', 火 [for] 'fire' is the semantic radical which gives a cue to the meaning of the character (as one needed fire to light an oil lamp in the olden days), and 登 [dangI] 'climb' is the phonetic radical which gives a cue to the pronunciation of the compound character. Unlike the assembled phonology in English, the pronunciation of a Chinese character may be derived directly from its phonetic radical

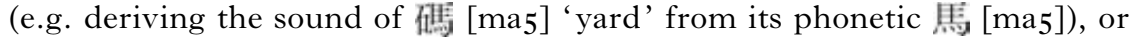
indirectly by making an analogy with another character having the same phonetic radical (e.g. associating the sound of 硅 [ma5] 'yard' with 蚟 [ma5] 'ant'). The former is analogous to the regularity effect in English while the latter reflects a consistency effect. These script-sound regularities/ consistencies are called orthography-phonology correspondence (OPC) rules in Chinese (e.g. Ho \& Bryant, I 997). Knowledge of phonetic radicals has been reported to be an important correlate of reading performance in Chinese (e.g. Ho, Ng \& Ng, 2003; Ho, Yau \& Au, 2003). The present study examined how well Chinese dyslexic children were able to make use of the phonological regularity of phonetic radicals in learning unfamiliar Chinese words. According to some statistics, the predictive accuracy of the pronunciation of an ideophonetic compound character from its phonetic radical is about $40 \%$ (e.g. Shu et al., in press). This drops to around $25 \%$ if tone is taken into consideration (e.g. Shu et al., in press). Thus, associations between script and sound in Chinese do not appear as strong as those in alphabetic languages. This would lead to the suggestion that associate learning ability might be particularly important in learning to read Chinese and this would also be examined in the present study.

\section{COGNITIVE DEFICITS IN CHINESE DEVELOPMENTAL DYSLEXIA AND PAIRED-ASSOCIATE LEARNING IN CHINESE}

Because Chinese characters are visually distinctive and complicated, people normally think that those who have difficulty in visual processing would have problems learning to read Chinese. Contrary to this common belief, visual deficit was not found to be the major problem in Chinese dyslexic children. Instead, there are multiple causations to Chinese developmental dyslexia. As discussed earlier, rapid naming deficit and orthographic deficit were found to be the two most dominant types of cognitive deficits in Chinese dyslexic children (Ho et al., 2002; Ho et al., 2004). As suggested by

[I] All pronunciation notes for Chinese characters in this paper are Cantonese pronunciations. The Linguistic Society of Hong Kong numerical convention for Cantonese tone has been used. For instance, in the syllable [dang I], ' $\mathrm{I}$ ' means that the syllable is in the first tone, i.e. a high level tone. 
Manis et al. (1999), rapid naming deficit may reflect difficulty of learning arbitrary associations between print and sound. This leads to the question of whether visual-verbal associate learning is a significant contributor to reading success and failure in Chinese, a system with rather arbitrary associations between script and sound. However, research on this topic in Chinese has been scarce. Among these few studies, Huang \& Hanley ( I 995) examined the role of visual skills in learning to read Chinese. They found that Visual Paired-Associates (a visual-verbal associate test) was the best predictor of Chinese word reading among the 8- to 9-year-old Chinese children both in Taiwan and in Hong Kong. However, in another of their studies, the same task administered to the Taiwan children at the age of 6 failed to predict the children's character reading performance one year later (Huang \& Hanley, I 997). These findings are inconsistent with those of their previous study and so far no research has been reported on visual-verbal associate learning of Chinese dyslexic children.

\section{AIMS OF THE PRESENT STUDY}

Based on the above literature review, the present study aimed to investigate (I) whether Chinese dyslexic children had difficulty in visual-verbal pairedassociate learning; (2) whether they had problem with long-term retention of over-learned materials, hence an indirect indicator of their possible problem in automatization; and (3) whether these children were able to use the phonetic radical (the orthographic unit that encodes sound in Chinese characters) effectively for learning new words. The first two questions addressed the learning deficit issue and the third tapped an important aspect of the orthographic domain. A word learning task was used as a measure of paired-associate learning in the present study. Half of the words in this learning task contained characters with reliable sound cues from the phonetic radical and half did not. The children's understanding and application of phonetic knowledge was tested by examining how well they learned the two types of new words. A familiar word writing task was employed to measure the children's long-term learning and retention of over-learned materials.

\section{METHOD}

\section{Participants}

There were altogether I ${ }_{5}$ Hong Kong Chinese primary school children participating in this study. Of them, 36 had developmental dyslexia and their mean age was $8 ; 8$. They were referred by the local education authority. All of them had normal intelligence (i.e. with IQ 85 or above). Their literacy composite score and at least one cognitive composite score 
were at least one standard deviation below their respective age means in the Hong Kong Test of Specific Learning Difficulties in Reading and Writing (HKT-SpLD) (Ho, Chan, Tsang \& Lee, 2000). They were carefully screened to ensure that they had sufficient learning opportunities (for instance new immigrants were excluded) and they did not have any suspected brain damage, uncorrected sensory impairment, serious emotional or behavioural problems.

The remaining 69 participants were normally achieving children recruited from four representative primary schools in Hong Kong. Thirty-six of these children served as CA controls (matched on chronological ages) and another 33 served as RL controls (matched on reading levels) for the dyslexic group. These 69 children had grade-appropriate reading achievement and normal intelligence. These controls were carefully selected to match on age, IQ, and reading level of the dyslexic group (see Table I).

\section{Materials and procedures}

All the children in this study were assessed individually on an intelligence test, three literacy subtests of the HKT-SpLD, a word learning task, and a familiar word writing task.

\section{Raven's standard progressive matrices}

This is a standardized test of nonverbal intelligence. There are altogether 60 items. Each item consists of a target visual matrix with one missing part. The children were asked to select, from six to eight alternatives, the part that best completed the matrix. Scoring procedures were based on the local norm established by the former Hong Kong Education Department in 1986.

\section{The Hong Kong Test of Specific Learning Difficulties in Reading and Writing : literacy subtests}

Three literacy subtests of the HKT-SpLD, namely Chinese Word Reading, One-minute Reading, and Chinese Word Dictation, were administered. In the Chinese Word Reading subtest, the children were asked to read aloud I 50 Chinese two-character words in the order of graded difficulty. The test was discontinued when the child failed to read I 5 words consecutively. There were 90 simple Chinese two-character words in the One-minute Reading subtest. The children were asked to read aloud each word as quickly and as accurately as possible within one minute. In the Chinese Word Dictation subtest, the children were asked to write in a dictation 48 Chinese two-character words. The test was discontinued when the child failed to write correctly in 8 consecutive words. 
TABLE I. Characteristics of the three groups of participants

\begin{tabular}{|c|c|c|c|c|c|}
\hline \multirow{7}{*}{ N } & Characteristic/task & $\begin{array}{c}\text { Dyslexic } \\
\left(n=3^{6}\right)\end{array}$ & $\begin{array}{l}\text { CA control } \\
\quad\left(n=3^{6}\right)\end{array}$ & $\begin{array}{l}\text { RL control } \\
(n=33)\end{array}$ & $F$ value \\
\hline & & Mean (S.D.) & Mean (s.D.) & Mean (S.D.) & $F(2, I O 2)$ \\
\hline & Age (years; months) & $8 ; 8(0 ;$ I I $)$ & $8 ; 9$ (0; I I ) & 6 ; I I (o; Io) & $47 \cdot 50^{* * *}(\mathrm{D}=\mathrm{CA}, \mathrm{D}>\mathrm{RL})$ \\
\hline & $\mathrm{IQ}$ & IOI.6 (I $3 \cdot 0)$ & $102 \cdot 4(10 \cdot 9)$ & $102 \cdot 3(12 \cdot 4)$ & $0.05(\mathrm{D}=\mathrm{CA}, \mathrm{D}=\mathrm{RL})$ \\
\hline & Chinese word reading & $48 \cdot 3(24 \cdot 4)$ & $104 \cdot 3(2 \mathrm{I} \cdot 5)$ & $49 \cdot 3(27 \cdot 4)$ & $60 \cdot 87 * * *(\mathrm{D}<\mathrm{CA}, \mathrm{D}=\mathrm{RL})$ \\
\hline & Chinese one-minute reading & $39 \cdot 3($ I I $\cdot 8)$ & $69 \cdot 7($ (13.9) & $45 \cdot 9(\mathrm{I} 6 \cdot 8)$ & $45 \cdot$ I I*** $(\mathrm{D}<\mathrm{CA}, \mathrm{D}=\mathrm{RL})$ \\
\hline & Chinese word dictation & $25 \cdot 0($ ( $3 \cdot 0)$ & $59 \cdot 2($ I $7 \cdot 8)$ & $29 \cdot 6(\mathrm{I} 6 \cdot \mathrm{I})$ & $49 \cdot 63^{* * *}(\mathrm{D}<\mathrm{CA}, \mathrm{D}=\mathrm{RL})$ \\
\hline
\end{tabular}

7
0
$y$
$i$
$i$
$i$

Note: $* * * *<0.00$ I. D : Dyslexic group. CA: CA control group. RL: RL control group. 
TABLE 2. Sample items of the word learning task

\begin{tabular}{|c|c|c|}
\hline Target word & Phonetic radical & Meaning of the word \\
\hline \multicolumn{3}{|l|}{ Regular words: } \\
\hline 酸酊 [ming 5 ]-[ding $\mathrm{I}]$ & 名丁 [ming4]-[ding I] & Dead drunk \\
\hline 猙㲘 [dzang I]-[ning4] & 爭跱 [dzang I]-[ning4] & Hideous looks \\
\hline \multicolumn{3}{|l|}{ Irregular words: } \\
\hline 訾踹 [tsau4]-[tsy4] & 尋著 [sau6]-[dzy3] & Hesitate \\
\hline 累鰲 [loey5]-[dzoey6] & 田敖 [tin4]-[ngou4] & Wordy, troublesome \\
\hline
\end{tabular}

\section{Word learning}

In this task, the children were asked to learn the pronunciation of 8 unfamiliar Chinese two-character words at senior elementary levels. Half of the words had phonetic radicals providing reliable sound cues (regular words), and half had not (irregular words) (see Table 2 for sample items). Regular words were defined as those whose phonetic radicals and the corresponding characters were homophones (i.e. identical syllables with the same tones, e.g. the phonetic 丁 [ding I] in the character 酊 [ding I]) or partial homophones (i.e. identical syllables with different tones, e.g. the phonetic 名 [ming4] in the character 醇 [ming 5$]$ ). Ho \& Bryant (1997) demonstrated that children as young as first grade showed a significant regularity effect in reading Chinese characters with these two types of phonetics. Irregular words in this task were defined as those whose phonetic radicals differed in onsets and/or rhymes from the corresponding characters (e.g. the phonetic 田 [tin4] in the character 累 [loey5]). Each word was printed on a separate card. There were three parts in this learning task pretraining, training, and delayed recall. In the pretraining part, the children were asked to name all the words before training in order to measure their baseline level. In the training part, the children were first taught the pronunciation and meaning of each word. The cards were then shuffled and they were asked to recall the name of each word. Immediate feedback and corrective training were given for each word. There were Io trials in this part and the order of words for naming was randomized in each trial. Without giving prior notice to the children, a surprise delayed recall took place about one hour after the training part. The children were asked to name each word again. They were also asked to name the phonetic radicals appeared in the target words of this task. The Dyslexic group (39.5\%) was found to know significantly less number of the phonetic radicals than the CA control group $(63.9 \%)$ but showed a similar correct rate as the RL control group $(40 \cdot 9 \%)[F(2,100)=39 \cdot 39, p<0 \cdot 00 \mathrm{I}]$. 


\section{Familiar word writing}

The children were asked to write some familiar words which they came across very often in school. There were two types of words-personal information and general information. Personal information included the child's own name and the name of his/her school. General information included school subjects, seasons, festivals, and local district names, etc. These were overlearned or environmentally exposed materials.

\section{RESULTS}

\section{Word learning}

Correct rate analyses. A three-way ANOVA: (3) group $\times(2)$ word type $\times$ (I 2 ) trials was conducted on the correct rate of the word learning task. All the main effects and interaction effects were significant (all $F \mathrm{~s}$ $>3.3$, all $p$ s $<0.05$ ). Post hoc comparisons by Tukey HSD showed that on average the dyslexic children performed significantly less well than the CA controls and similarly with the RL controls. The children learned regular words better than irregular ones. The average performance of these children also improved over trials except from Trial 6 to Trial 7 and from Trial 8 to Trial 9 when regular and irregular items were combined.

We were most interested in the significant three-way interaction. To understand this interaction effect, the learning curves of the three groups of participants on learning regular and irregular words were shown in Figures $\mathrm{Ia}$ and $\mathrm{Ib}$ respectively. It appears that the CA control group performed better than the other two groups on both regular and irregular words. The learning curves of the Dyslexic and RL control groups greatly overlapped on regular words but somewhat deviated on irregular words. To test this observation, two two-way ANOVAs: (2) group $\times$ (I2) trials were conducted to compare the learning pattern of the Dyslexic and RL control groups on regular and irregular words separately. It was found that the interaction effect for regular words was not significant but that for irregular words was marginally significant $[F(\mathrm{I} \mathrm{I}, 57)=\mathrm{I} \cdot 85, p=0.067]$. We believe that the effect would be more robust if there were more items for each type of words. The results suggest that the learning pattern of the Dyslexic group on regular words was similar to that of the RL control group, whereas the Dyslexic group tended to learn irregular words less well over trials than the RL control group.

Rate of forgetting. Rate of forgetting was calculated by (recall at the Ioth trial-delayed recall)/recall at the roth trial. Result of the one-way ANOVA: group (3) showed that the three groups did not differ significantly on the rate of forgetting. It appears that the dyslexic children had more problems with acquisition than with maintenance. 
(a)

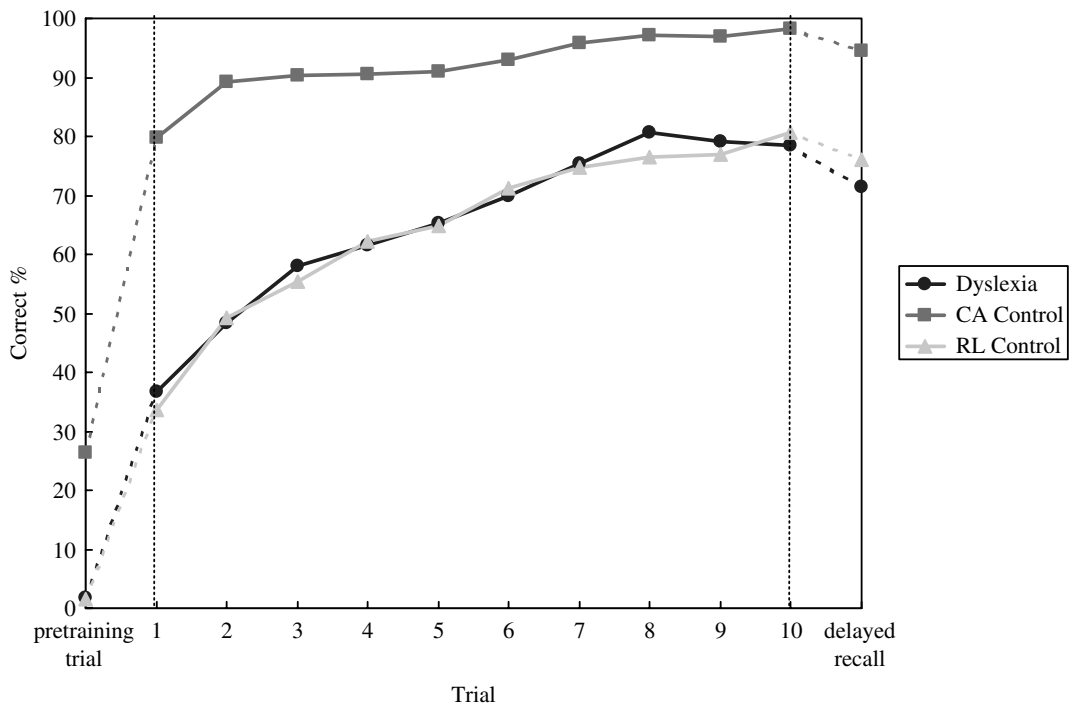

(b)

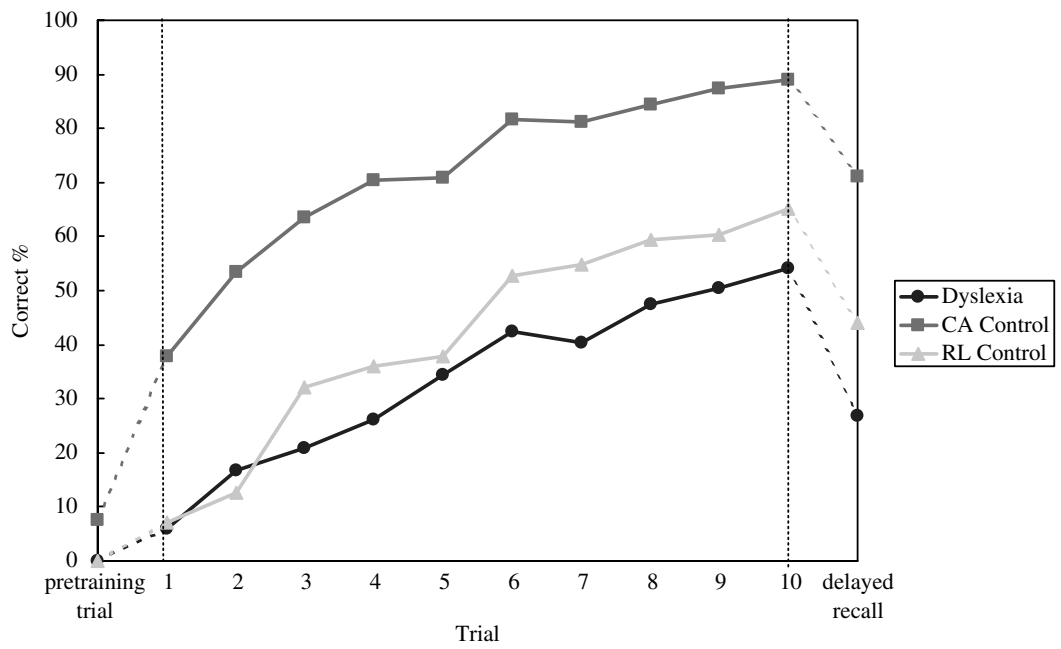

Fig. I. The learning curves of the three groups of participants on (a) regular words in the word learning task. (b) irregular words in the word learning task.

Error analyses. We also analysed errors the children in the Dyslexic group and the RL control group made in the word learning task. Table 3 shows the definitions, examples, and mean number of the various types of 
TABLE 3. Mean number of errors for the dyslexic and reading level control groups on the word learning task

\begin{tabular}{|c|c|c|c|}
\hline Type of error & Definition and example & Dyslexic & $\begin{array}{c}\mathrm{RL} \\
\text { Control }\end{array}$ \\
\hline Orthographic & $\begin{array}{l}\text { The semantic or phonetic radical of the } \\
\text { response characters was the same as that of the } \\
\text { target characters e.g. 狰 [dzang I] was read as } \\
\text { 猜 [tsaai ], a character with the same semantic } \\
\text { radical e.g. 鏑 [soeng I] was read as 宔 } \\
\text { [joeng6], a character with the same phonetic } \\
\text { radical }\end{array}$ & $2 \cdot 97$ & I.06 \\
\hline Phonological & $\begin{array}{l}\text { The onset or rime of the response characters } \\
\text { was the same as that of the target characters } \\
\text { e.g. 睡有! [fuk7]-[juk7] was read as 灰玉 } \\
\text { [fuir]-[jukg] }\end{array}$ & $2 \cdot 28$ & $3 \cdot 2 \mathrm{I}$ \\
\hline Semantic & $\begin{array}{l}\text { The response word was semantically related to } \\
\text { the target word e.g. 稀罕 'rare' was read as } \\
\text { 䧾得 'difficult to get' }\end{array}$ & $0 \cdot 36$ & 0.12 \\
\hline $\begin{array}{l}\text { Intra-wordlist } \\
\text { interference }\end{array}$ & 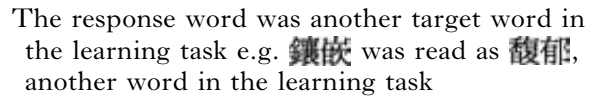 & $3 \cdot 42$ & $5 \cdot 5^{8}$ \\
\hline Word association & $\begin{array}{l}\text { The response word was a free association of the } \\
\text { target word in that they share a homophonic } \\
\text { character e.g. 鑲能 [soeng } \mathrm{I} \text {-[ham 3] was } \\
\text { read as 相撞 [soengI]-[dzong6] }\end{array}$ & $2 \cdot 64$ & I.67 \\
\hline Other & $\begin{array}{l}\text { Other responses that cannot be classified into } \\
\text { the above categories }\end{array}$ & $\mathrm{I} \cdot 03$ & I.09 \\
\hline Total & $\begin{array}{l}\text { Total number of errors excluding 'did not } \\
\text { know' }\end{array}$ & $12 \cdot 69$ & $12 \cdot 73$ \\
\hline Did not know & The child just responded not knowing the word & $84 \cdot 39$ & $78 \cdot 09$ \\
\hline
\end{tabular}

errors in this task. The number of errors was calculated based on the errors made in the ro learning trials of the 8 words. We excluded the 'did not know' errors for further analyses as they were not informative about the types of strategies the children might have employed. We conducted a one-way MANOVA to examine group differences on error types with the total number of errors (excluding 'did not know') as a covariate. The overall main effect of group was significant $[F(5,62)=2.475, p<0.05]$. Results of separate ANOVAs showed that the main effect of group for orthographic errors was statistically significant $\left[F(\mathrm{I}, 66)=9.8_{\mathrm{I}}, p<0.0 \mathrm{I}\right]$, and those for intra-wordlist $[F(\mathrm{I}, 66)=3.9 \mathrm{I} 2, p=0.052]$ and word association errors $[F(\mathrm{I}, 66)=3.328, p=0.073]$ were marginally significant. The results showed that the Dyslexic group made higher proportions of orthographic and word association errors but a lower proportion of intra-wordlist interference errors than the RL control group. 
TABLE 4. Results of the familiar word writing task for the three groups of participants

\begin{tabular}{|c|c|c|c|}
\hline Task & $\begin{array}{c}\text { Dyslexic } \\
(n=36)\end{array}$ & $\begin{array}{l}\text { CA control } \\
\quad(n=36)\end{array}$ & $\begin{array}{c}\text { RL control } \\
\quad(n=33)\end{array}$ \\
\hline & $\%$ correct & $\%$ correct & $\%$ correct \\
\hline & Mean (S.D.) & Mean (S.D.) & Mean (S.D.) \\
\hline \multicolumn{4}{|l|}{ Personal information } \\
\hline Own name & $80 \cdot 6(23 \cdot I)$ & $99 \cdot I(5 \cdot 5)$ & $100 \cdot 0(0)$ \\
\hline School name & $66 \cdot 1(24 \cdot 7)$ & $97 \cdot$ I $(6 \cdot 8)$ & $68 \cdot 6(38 \cdot 9)$ \\
\hline General information & $57 \cdot 2(18 \cdot 5)$ & $87 \cdot 9(9 \cdot 3)$ & $65 \cdot 5($ I6.5) \\
\hline
\end{tabular}

\section{Familiar word writing}

Table 4 presents the mean correct rates and standard deviations of the Familiar word writing task for the three groups of participants. A MANOVA was conducted to examine any group differences on this task. The main effects of group in the MANOVA and in separate ANOVAs were all significant (all $F$ s $>$ I 5.05, all $p$ s <0.00I). Post hoc comparisons by the Tukey HSD showed that the dyslexic children wrote all the materials significantly less well than the CA controls (all ps <०.০०I). As compared with the performance of the RL controls, the dyslexic children wrote less accurately their own name $(p<0.00 \mathrm{I})$ and familiar words of general information $(p=0.066)$, but similarly their school name.

\section{DISCUSSION}

The primary aim of the present study was to examine whether Chinese dyslexic children have difficulties in word learning, a particular instance of visual-verbal associate learning. We have compared Chinese dyslexic children with average readers on their learning of new Chinese words, their utilization of phonetic radicals in learning these words, and the long-term retention of overlearned materials. Our findings are discussed below.

\section{Word learning deficit in Chinese dyslexic children}

The present findings suggest that Chinese dyslexic children tend to have a deficit in learning new words. Although by definition dyslexic children tend to have difficulties in word learning, we will discuss below how the present findings help to clarify where the specific difficulties may lie in the case of Chinese.

\section{The use of phonetic radicals in word acquisition}

With regard to learning new words, the present findings show that Chinese dyslexic children have more problems with acquisition than with 
maintenance in the short-term, i.e. when they are asked to recall words within a couple of hours. The dyslexic children in the present study remembered significantly fewer learned words than the CA controls but the rate of forgetting after one hour of training was comparable across the three groups. However, there might be greater group differences in forgetting if a longer retention interval (e.g. more than a day) were used.

The most interesting and important finding in the present study was that the dyslexic children learned irregular words less well over trials than did the RL controls but the two groups performed similarly in learning regular words. We should note that the two groups knew equal number of phonetic radicals of the target words that were used for getting phonological information. This finding indicates that Chinese dyslexic children are able to make use of phonetic radicals, the orthographic unit in a Chinese character that encodes phonological information, in learning new words. However, they find learning and recalling irregular characters particularly difficult.

There are at least three hypotheses which may explain the difficulties that Chinese dyslexic children have in learning irregular characters. First, dyslexic children may easily confuse orthographically similar characters. Second, without the help of reliable phonetics, the children may find learning new script-sound associations difficult. Third, they may have difficulty remembering the sound of new words. These hypotheses are not necessarily mutually exclusive. Results of the error analyses on the word learning task as outlined below will help to examine these hypotheses.

Regarding the first hypothesis, the Dyslexic group was found to commit a significantly higher proportion of orthographic errors (largely involving the confusion of characters with the same phonetics) than the RL control group. Chinese dyslexic children seem to find orthographically similar characters very confusing. They would face added difficulty when the same phonetics are paired up with different sounds in irregular characters. This may reflect that the dyslexic children have weak orthographic representation of words and poor linking between the orthographic and phonological processors. This suggestion is consistent with the previous finding that orthographic deficit is one of the dominant cognitive deficits in Chinese dyslexic children (Ho et al., 2004).

Regarding the second hypothesis, the Dyslexic group was found to commit a lower proportion of intra-wordlist interference errors than the RL control group. In other words, the younger readers had a greater tendency to mix up names of the newly learned words. They remembered the new sound but not the new association. Thus, younger children, instead of dyslexic readers, seem to have more difficulty forming new associations of sound and visual form. Alternatively, the dyslexic children might have failed to remember the new sounds and thus showing less intra-wordlist interference errors. This leads to the examination of the third hypothesis. 
For the third hypothesis, the Dyslexic group was found to make a higher proportion of word association errors but not more phonological errors than the RL control group. In other words, Chinese dyslexic children do not seem to encode or remember Chinese syllables qualitatively differently from or worse than average readers. This is consistent with their relatively milder difficulty in phonological awareness. However, when there is no reliable phonological cue, dyslexic children easily confuse newly learned words with other words with homophonic characters in the mental lexicon. The children's confusion suggests that they have difficulty remembering new combinations of syllables that form new words. This may reflect their difficulty in remembering the sound of new words, weak morphological awareness, and general difficulty in oral vocabulary learning. However, these hypotheses require further examination as errors committed by the children other than 'did not know' are not high in the present study.

To summarize, Chinese dyslexic children tend to have difficulty acquiring new words, particularly irregular ones. This irregular word learning difficulty seems to be related to their weak orthographic representation and problem in remembering new sound or new combinations of sound. Their short-term retention of verbal materials seems to be comparable to that of average readers. The acquisition problem is an important learning deficit because difficulty in learning new irregular words implies possible problems in establishing long-term memory of word-specific representation, which is a definite hurdle for long-term word learning.

\section{Long-term retention}

Chinese dyslexic children do not appear to have specific problem in shortterm retention of words or their problem might show up under longer retention periods (i.e. more than an hour). Nicolson \& Fawcett (2000) and Messbauer et al. (2003) have also reported that dyslexic readers of alphabetic languages do not show particular problem in long-term retention of visual-motor and verbal materials. However, the present findings in familiar word writing show that Chinese dyslexic children remember some over-learned materials (e.g. their own name, school subjects and seasons) significantly less well than younger readers of the same reading level. The most striking finding was that on average the dyslexic children only wrote their own names $80 \%$ correctly even though they have practised writing their own names for at least 4 years starting from kindergarten. This suggests that dyslexic children are not only slow in acquisition but also require more practice for long-term retention of words. The inconsistent findings between past and the present studies suggest that the long-term retention problem of dyslexic readers may be confined to more difficult verbal tasks like spelling, but is not apparent in naming or visual-motor 
tasks. The long-term retention problem in word writing/spelling may be due to their poor initial acquisition and greater memory loss over a longer period of time.

\section{SUGGESTIONS FOR FUTURE RESEARCH}

We suggest the inclusion of different types of verbal and nonverbal learning tasks in future studies, and this would help to determine whether the learning deficit of Chinese dyslexic children is confined to word learning only. The proposed connection between word learning deficit and rapid naming deficit in Chinese dyslexia may also be examined in future research.

\section{REFERENCES}

Badian, N. A. (I995). Predicting reading ability over the long-term: the changing roles of letter naming, phonological awareness and orthographic processing. Annals of Dyslexia: An Interdisciplinary fournal XLV, 79-96.

Bowers, P. G. \& Wolf, M. (I993). Theoretical links among naming speed, precise timing mechanisms and orthographic skill in dyslexia. Reading and Writing 5(I), 69-85.

Bradley, L. \& Bryant, P. E. (1978). Difficulties in auditory organization as a possible cause of reading backwardness. Nature 27I, 746-7.

Ho, C. S.-H. \& Bryant, P. (r 997$)$. Learning to read Chinese beyond the logographic phase. Reading Research Quarterly 32(3), 276-89.

Ho, C. S.-H., Chan, D. W.-O., Lee, S.-H., Tsang, S.-M. \& Luan, V. H. (2004). Cognitive profiling and preliminary subtyping in Chinese developmental dyslexia. Cognition 9r, $43-75$.

Ho, C. S.-H., Chan, D. W.-O., Tsang, S.-M. \& Lee, S.-H. (2000). The Hong Kong Test of Specific Learning Difficulties in Reading and Writing. Hong Kong: Hong Kong Specific Learning Difficulties Research Team.

Ho, C. S.-H., Chan, D. W.-O., Tsang, S.-M. \& Lee, S.-H. (2002) The cognitive profile and multiple-deficit hypothesis in Chinese developmental dyslexia. Developmental Psychology 38(4), 543-53.

Ho, C. S.-H., Ng, T.-T. \& Ng, W.-K. (2003). A 'radical' approach to reading development in Chinese: the role of semantic radicals and phonetic radicals. Fournal of Literacy Research 35, 849-78.

Ho, C. S.-H., Yau, P. W.-Y. \& Au, A. (2003). Development of orthographic knowledge and its relationship with reading and spelling among Chinese kindergarten and primary school children. In C. McBride-Chang \& H.-C. Chen (eds), Reading development in Chinese children. Westport: Praeger.

Hoosain, R. (I99I). Psycholinguistic implications for linguistic relativity: a case study of Chinese. Hillsdale, NJ : Erlbaum.

Hulme, C. \& Snowling, M. (1992). Deficits in output phonology: an explanation of reading failure? Cognitive Neuropsychology 9, 47-72.

Huang, H. S. \& Hanley, J. R. (I 995). Phonological awareness and visual skills in learning to read Chinese and English. Cognition 54, 73-98.

Hunag, H. S. \& Hanley, J. R. (I 997). A longitudinal study of phonological awareness visual skills and Chinese reading acquisition among first-graders in Taiwan. International Journal of Behavioral Development 20(2), 249-68.

Kang, J. S. (I 993). Analysis of semantics of semantic-phonetics compound characters in modern Chinese. In Y. Chen (ed.), Information analysis of usage of characters in modern Chinese. Shanghai: Shanghai Education Publisher, in Chinese. 
Liberman, I. Y., Mann, V. A., Shankweiler, D. \& Werfman, M. (I982). Children's memory for recurring linguistic and non-linguistic material in relation to reading ability. Cortex $\mathbf{1 8}$, $367-75$.

Lyon, G. R. (1 995). Toward a definition of dyslexia. Annals of Dyslexia 45, 3-27.

Manis, F. R., Seidenberg, M. S. \& Doi, L. M. (I 999). See Dick RAN : rapid naming and the longitudinal prediction of reading subskills in first and second graders. Scientific Studies of Reading 3(2), I 29-57.

Mayringer, H. \& Wimmer, H. (2000). Pseudoname learning by German-speaking children with dyslexia: evidence for a phonological learning deficit. Fournal of Experimental Child Psychology 75, i i 6-33.

Messbauer, V. C. S. \& de Jong, P. F. (2003). Word, non-word, and visual paired associate learning in Dutch dyslexic children. Journal of Experimental Child Psychology 84, 77-96.

Messbauer, V. C. S., de Jong, P. F. \& van der Leij, A. (2002). Manifestation of phonological deficits in dyslexia: evidence from Dutch children. In L. Verhoeven, C. Celbro \& P. Reitsma (eds), Precursors of functional literacy, Amsterdam, The Netherlands: John Benjamin.

Miles, E. (2000). Dyslexia may show a different face in different languages. Dyslexia 6, I $93-20$ I

Nicolson, R. I. \& Fawcett, A. J. (I990). Automaticity: a new framework for dyslexia research? Cognition 30, I 59-82.

Nicolson, R. I. \& Fawcett, A. J. (2000). Long-term memory in dyslexic children. European Fournal of Cognitive Psychology 12(3), 357-93.

Olson, R. K., Rack, J. P. \& Forsberg, H. (I990). Profiles of abilities in dyslexic and readinglevel-matched controls. Poster presented at the Rodin Remediation Academy meeting at Boulder, CO.

Shu, H., Chen, X., Anderson R. C., Wu, N. \& Xuan, Y. (2003). Properties of school Chinese: Implications for learning to read. Child Development 74, 27-47.

Taylor, I. \& Taylor, M. M. (1995). Writing and literacy in Chinese, Korean and Fapanese. Philadelphia: John Benjamins.

Vellutino, F. R., Scanlon, D. M. \& Bentley, W. L. (r983). Interhemispheric learning and speed of hemispheric transmission in dyslexic and normal readers: a replication of previous results and additional findings. Applied Psycholinguistics 4, 209-28.

Vellutino, F. R., Scanlon, D. M. \& Spearing, D. (I995). Semantic and phonological coding in poor and normal readers. Fournal of Experimental Child Psychology 59, 76-I 23.

Wimmer, H. \& Mayringer, H. (200I). Is the reading-rate problem of German dyslexic children caused by slow visual processes? In M. Wolf (ed.), Dyslexia, fluency, and the brain. Maryland: York Press.

Windfuhr, K. L. \& Snowling, M. J. (200I). The relationship between paired associate learning and phonological skills in normally developing readers. Fournal of Experimental Child Psychology 8o, i6o-73. 